\title{
The Use of Surface Waves to Estimate In-Place Strength of Concrete
}

\author{
Gonzalo E. Gallo ${ }^{1}$ and John S. Popovics ${ }^{2}$
}

Received 31 May 2005, accepted 10 July 2005

\begin{abstract}
Non-destructive evaluation (NDE) techniques are needed to evaluate in-place strength of concrete in structures. Often mechanical wave propagation parameters are used to establish a correlation with strength. P-wave velocity measurements are most common for this purpose, but its application can be problematic. Here the utility of surface waves is investigated. Surface wave velocity and transmission (attenuation) properties are considered, where a self-compensating approach overcomes experimental difficulties usually experienced in transmission measurements. In this paper, the testing configuration is described and the concept of the self-compensating approach introduced. Then a test series is described: surface wave velocity and wave transmission and P-wave through thickness velocity data are collected from concrete slabs of different strengths. Relations between concrete strength, wave velocity and surface wave transmission are established. Surface wave velocity and normalized surface wave velocity data correlate well with in-place strength. Transmission data also are sensitive to concrete strength but data variation must be improved.
\end{abstract}

\section{Introduction}

In-place determination of concrete strength in structures is important for civil engineers. In some cases it is necessary to determine the capacity of an existing structure; in other cases quality control and quality assurance of newly-built construction must be established. At present, testing for concrete strength requires drilling core samples to make direct measurements. However this approach is time-consuming, expensive and destructive as it leaves behind undesirable discontinuities. In addition it is difficult to collect data in a statistically thorough manner; for example on average only six cores per lane for every $8 \mathrm{~km}$ of concrete pavement length are taken (Warnemuende and $\mathrm{Wu}, 2004$ ).

Non-destructive techniques that can accurately estimate compressive strength are therefore highly desirable. These techniques allow for faster, cheaper, and more statistically extensive testing. Many efforts to correlate through thickness ultrasonic $\mathrm{P}$-wave velocity (UPV) measurements with strength have been carried out (ACI, 2003). The UPV technique is prescribed in ASTM C 597. Despite these efforts, UPV has not evolved much since its development for this task and a significant degree of error with strength prediction, up to $20 \%$, remains even with the use of calibration curves (Popovics et al., 1989). A practical limitation of through thickness UPV is that it requires two-sided access to the tested

\footnotetext{
${ }^{1}$ Graduate Student, Civil and Environmental Engineering, University of Illinois at UrbanaChampaign, USA.

${ }^{2}$ Assistant Professor, Civil and Environmental Engineering, University of Illinois at UrbanaChampaign, USA.

E-mail: johnpop@uiuc.edu
}

structure, which is not suitable for many structures like concrete pavements. Some argue that, in fact, there is currently no robust method for determining in-place strength of concrete non-destructively (Warnemuende and $\mathrm{Wu}, 2004)$.

The use of surface waves is proposed here as an alternative to P-waves to estimate compressive strength. The advantages of surface waves are that they are easily generated, they require only one-sided access and multiple signal parameters may be obtained to reduce data variability while improving sensitivity. The signal parameters considered in the present investigation are surface wave velocity and transmission, which is measured using a self-compensating technique. Previous research has shown that wave transmission or attenuation is more sensitive to internal cracks and porosity than wave velocity (Sellick et al., 1998). Since internal porosity and cracks affect concrete strength, it is logical to conclude that wave transmission is more sensitive to concrete strength variations than wave velocity. In this study, tests on plain concrete laboratory specimens are reported. The internal moisture content, surface roughness and presence of internal steel reinforcing bars in concrete could affect the obtained results but are beyond the scope of this paper. We intend to examine these issues in subsequent studies.

\section{Velocity measurements}

Through thickness P-wave velocity measurements are obtained as specified in ASTM C597. A pulser sends a high-voltage, short-duration voltage signal to a transducer causing it to vibrate at its resonant frequency thereby generating a P-wave pulse. At the same time, an electronic timer is switched on. The P-wave pulse leaves the transducer and is transferred into the concrete through a coupling medium. The P-wave then travels 
through the specimen and is received by a transducer coupled to the opposite concrete surface. When the signal is received, the timer is switched off and the travel time is displayed. The direct path length between the transducers is divided by the measured travel time and the pulse velocity is obtained (ACI, 2003).

Surface wave velocity measurements are obtained from two sensors (accelerometers) placed at a known distance along a path on the surface of the specimen. An impact is applied close to one of the sensors and along the line defined by the sensors. The time required for the signal to travel from the near sensor to the far sensor is recorded. The ratio of the spacing distance to the recorded time is taken as the surface wave velocity. In this study, the sensor spacing was five centimeters and the impact source was a mechanical impactor based on high-speed stroke magnets. Figure 1 shows the signals detected by the near and far sensors. The time lapse between the first significant signal features, in this case the valleys, of both is taken as the travel time of the surface wave (Cho, 2003).

\section{Principles of self-compensating transmission technique}

The self-compensating technique uses four stress wave signals to determine the surface-wave transmission between two points. The principle of this approach has been fully explained elsewhere (Popovics et al., 2000) and will be only briefly described here. Consider two wave sensors, spaced a known distance, attached on the surface of an elastic solid, such as in the sketch in Fig. 2. An impact is applied on the surface along the line of the sensors, but not between them. The generated wave propagating along the surface will be first detected by the near sensor (location 2) and then by the far sensor (location 3). The stress wave signal received by the near sensor can be represented in the frequency domain by $\mathrm{V}_{12}$ :

$$
V_{12}=A_{1} d_{12} S_{2}
$$

where $A_{1}$ is the sending response function and $S_{2}$ the

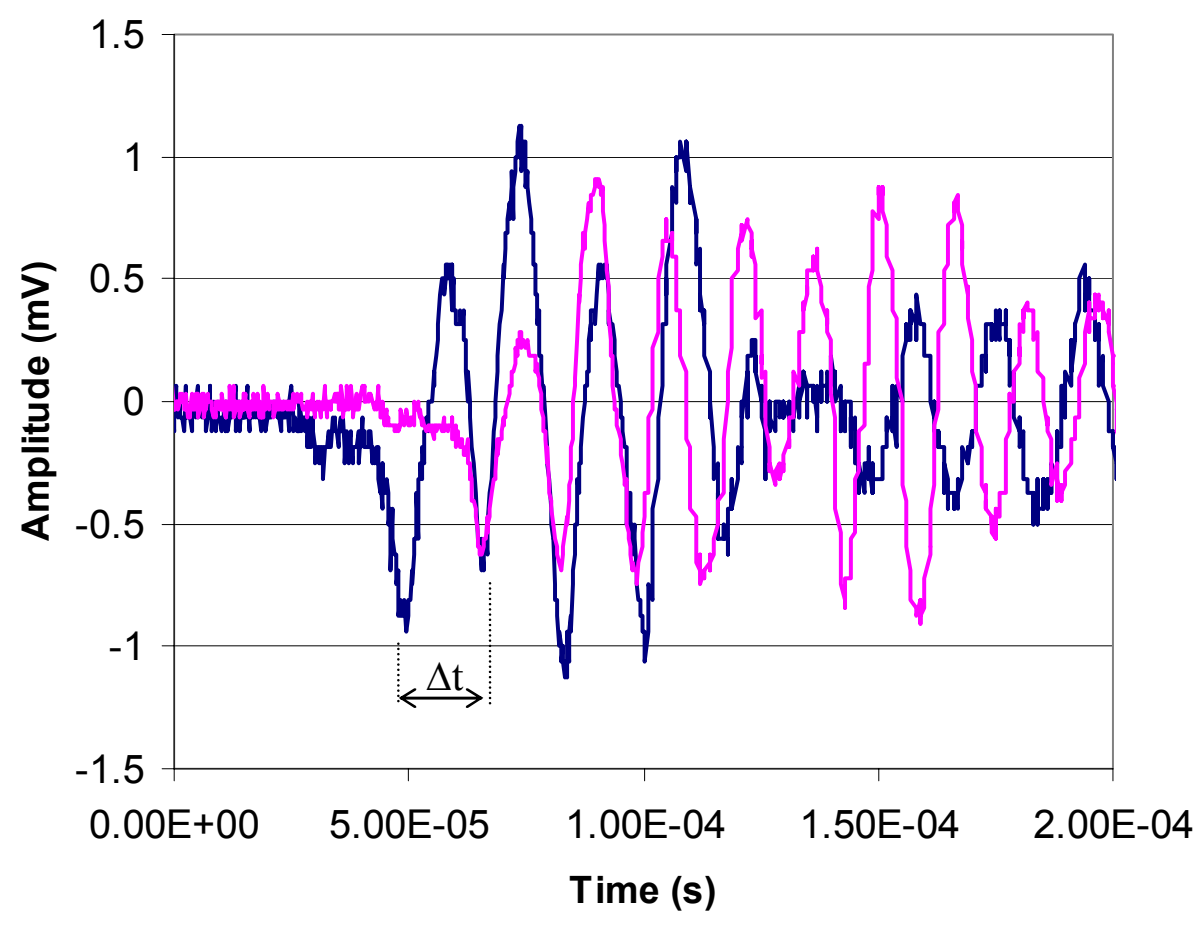

Fig. 1 Surface wave velocity signals. Black line is near sensor and grey line far sensor.

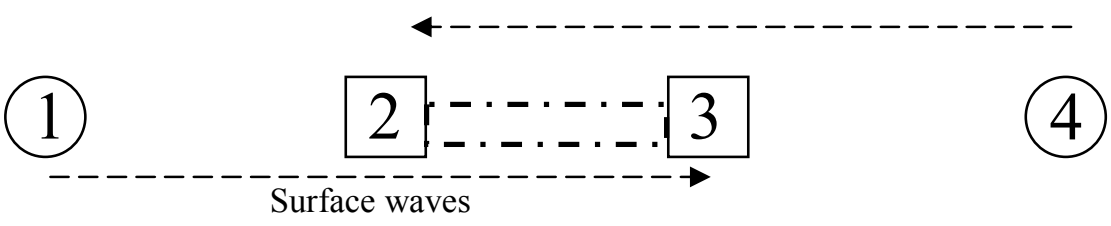

Fig. 2 Sketch (plan view) of self-compensating wave transmission testing configuration. The circles represent wave sources and the squares wave receivers. 
response function received by the near sensor. The term $\mathrm{d}_{12}$ characterizes the signal transmission function between Locations 1 and 2 (Popovics et al., 2000).

Similarly, the stress wave signal generated at 1 and detected by the far sensor is characterized by

$$
V_{13}=A_{1} d_{12} d_{23} S_{3}
$$

where $S_{3}$ represents the receiving function of the far sensor and $\mathrm{d}_{23}$ the transmission function between the two sensors, which is the term of interest. If now another impact is applied at Location 4 an additional pair of equations is obtained. By simple manipulation of the $V_{i j}$ terms, an expression of the transmission between the two sensors can be defined as:

$$
\left|d_{23}\right|=\left|\sqrt{\frac{V_{13} V_{42}}{V_{12} V_{43}}}\right|
$$

This manipulation eliminates the sending $\left(\mathrm{A}_{\mathrm{i}}\right)$ and receiving $\left(\mathrm{S}_{\mathrm{i}}\right)$ functions and renders a transmission value independent of sensor type, coupling condition, or impact used in the experimental setup. The term $d_{23}$ is simply the ratio of the signal amplitude at the far sensor to the near sensor and higher number implies a larger signal transmission between them (Popovics et al., 2000). A value of 1 would imply that there is perfect transmission, and thus no loss of signal energy between sensors, while a value of zero would indicate that the signal energy is totally lost along the path between the two sensors.

Since the manipulations are done in the frequency domain, a broad range of frequencies may be used at once to provide more data to use in computations. It is important therefore to determine a frequency region of acceptably high signal to noise ratio and consistency, where the variability of nominally identical transmission data is minimized. The signal consistency function is therefore determined to establish the variability of the signal. It is the quotient of the geometric and arithmetic averages of a set of repeated signals in the frequency domain (Popovics et al., 2000). Acceptable signals have consistency above 0.99 . In Fig. 3, an example of a signal consistency function and the acceptable frequency range is shown. The usable frequency range in the transmission tests was generally from $110 \mathrm{kHz}$ to $130 \mathrm{kHz}$.

\section{Experimental setup}

\subsection{Test specimens}

Velocity and transmission measurements were performed on square concrete slabs with nominal dimensions $50 \times 50 \times 10 \mathrm{~cm}$. The concrete mixtures were designed to consider several material parameters that may affect concrete strength, velocity and transmission. The fresh concrete was mixed with a Lancaster pan mixer. The process started with dry mixing of the ingredients for 2 minutes. After this time, water and air entrainer, if appropriate, were added and mixing continued for 1 additional minute. Manual mixing was briefly done to achieve homogeneity, since some material was left in the bottom of the pan untouched. Then the blend was subjected to another minute in the pan mixer. A first set of specimens was cast using water/cement ratios (w/c)

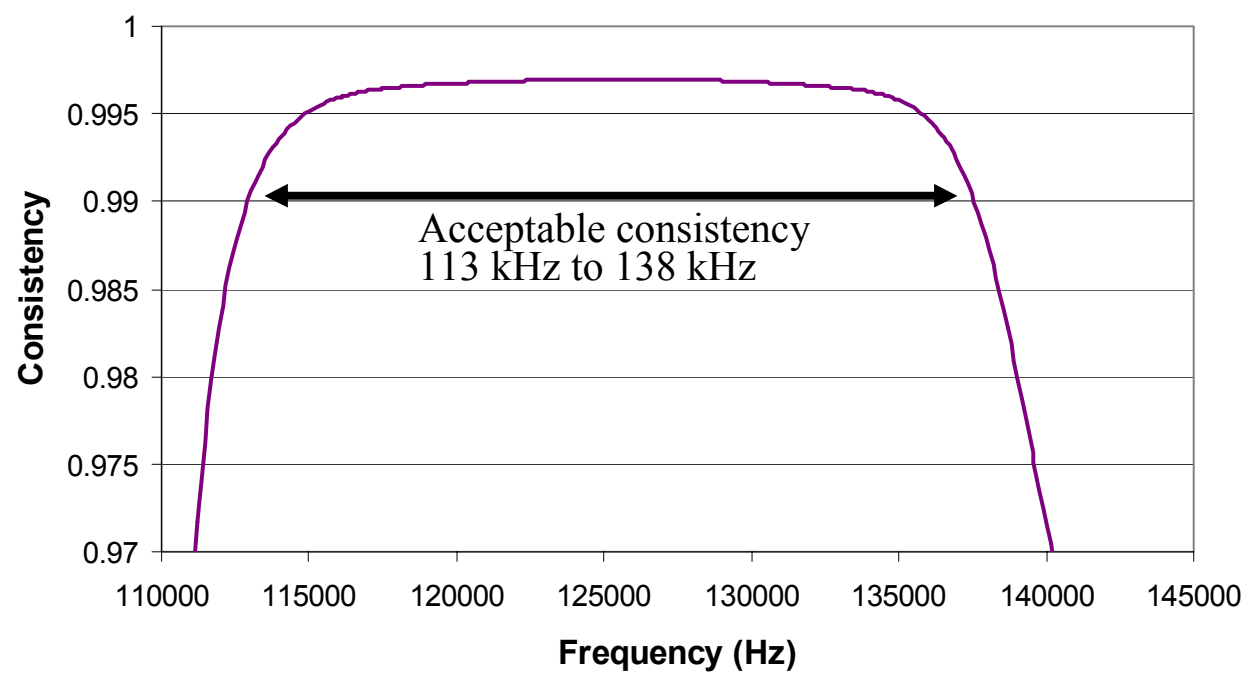

Fig. 3 Signal consistency function showing range of acceptable frequencies (113 kHz to $138 \mathrm{kHz}$ ). Signal obtained from an air entrained concrete sample, $w / c=0.40$. 
varying from 0.4 to 0.52 . A similar group of slabs was made with entrained air. The third set of specimens was used to analyze variations during the hydration process and with changes in the cement content, but at fixed w/c Table 1 provides details of the composition and properties of the slabs. The labels indicate the type of mixture and the w/c. AE designates air-entrained and NAE non air-entrained mixtures. In the case of the mixtures with varying cement contents, $\mathrm{L}$ indicates a lean mix (low cement content), $\mathrm{N}$ for that with a normal composition according to ACI guidelines, and R for a rich mix (high cement content). The slabs contained no internal reinforcement.

The aggregates were a crushed limestone with a maximum nominal size of $25 \mathrm{~mm}$ and well graded sand. No mineral admixtures were added. After consolidation, the surface of the slabs was hand finished with a steel trowel. The slabs were cured in a moist room (100\% humidity, $\left.23{ }^{\circ} \mathrm{C}\right)$ until testing. Companion $100 \times 200$ $\mathrm{mm}$ cylinders were cast for all mixtures to measure the compressive strength at 28 days. In addition, compressive strengths for mixes with fixed w/c were measured at 7 and 14 days after mixing. Compressive strength was measured according to ASTM C-39 and the strength data, an average of three cylinders, are shown in Tables $\mathbf{2}$ and 3.

\subsection{Wave velocity and transmission measure- ments}

A plan view of the experimental testing configuration is shown in Fig. 2. Two sensors and two impact locations are placed along a line. The spacing between the two sensors is the same as that between the near sensor and the impact location. This makes the maximum theoretical transmission value, in the case were only beam spreading losses are present, to be 0.71 . This is because surface wave amplitude decay for a point source of waves is proportional to $1 / \sqrt{r}$, where $r$ is the distance

Table 1 Concrete test specimen mixture description.

\begin{tabular}{|l|c|r|r|}
\hline \multirow{2}{*}{ Label } & $\begin{array}{c}\text { Composition } \\
\text { (by mass) }\end{array}$ & Slump & $\begin{array}{c}\text { Air } \\
\text { Content }\end{array}$ \\
\cline { 2 - 4 } & c:w:fa:ca & \multicolumn{1}{c|}{$\mathrm{mm}$} & \multicolumn{2}{c|}{$\%$} \\
\hline AE40 & $1: 0.40: 1.40: 2.70$ & 18 & 3.3 \\
\hline AE44 & $1: 0.44: 1.71: 3.03$ & 44 & 4.4 \\
\hline AE48 & $1: 0.48: 1.90: 3.30$ & 64 & 6.3 \\
\hline AE52 & $1: 0.52: 2.12: 3.58$ & 95 & 5.1 \\
\hline NAE40 & $1: 0.40: 1.25: 2.43$ & 64 & 1.2 \\
\hline NAE44 & $1: 0.44: 1.45: 2.67$ & 89 & 1.5 \\
\hline NAE48 & $1: 0.48: 1.65: 2.92$ & 102 & 1.5 \\
\hline NAE52 & $1: 0.52: 1.84: 3.16$ & 95 & 2.7 \\
\hline L48 & $1: 0.48: 2.18: 4.53$ & 44 & 10.3 \\
\hline N48 & $1: 0.48: 1.90: 3.30$ & 89 & 7.3 \\
\hline R48 & $1: 0.48: 1.70: 2.38$ & 216 & 5.5 \\
\hline
\end{tabular}

along the path that the signal must travel to reach the transducer (Achenbach, 1984). Nominally, the spacing between sensors and between the wave source and the near sensor is $50 \mathrm{~mm}$.

An automatic impactor was used as the wave source. This is a powered solenoid which permits a single controlled impact to be applied on the concrete surface. It is connected to a digital oscilloscope to initiate the acquisition process of the sensors. The sensors were miniature accelerometers. They were mounted on the concrete surface by a bonding agent. These accelerometers have a sensitivity of $10.89 \mathrm{mV} / \mathrm{g}$ at $100 \mathrm{~Hz}$. Their resonant frequency is close to $80 \mathrm{kHz}$ and the flat frequency response range is from 3 to $10000 \mathrm{~Hz}$. The sensors, through different channels, are connected to a digital oscilloscope by signal conditioners/amplifiers. A computer acquires the signals from the oscilloscope, through a GPIB interface, and processes them. Five time domain signals, which result from five repeated impacts, are collected by each sensor and processed in the computer based on a common feature (the first significant valley) centered in the time window. Five transmission functions are computed and then averaged to obtain one

Table 2 Compressive strengths for mixtures with varying w/c ratios. Age 28 days.

\begin{tabular}{|l|r|r|}
\hline \multirow{2}{*}{ Label } & $\begin{array}{c}\text { Compressive } \\
\text { strength }\end{array}$ & \multirow{2}{*}{ w/c ratio } \\
\cline { 2 - 2 } & $\mathrm{MPa}$ & 0.40 \\
\hline NAE40 & 45.7 & 0.44 \\
\hline NAE44 & 40.2 & 0.48 \\
\hline NAE48 & 33.8 & 0.52 \\
\hline NAE52 & 34.7 & 0.40 \\
\hline AE40 & 39.2 & 0.44 \\
\hline AE44 & 31.0 & 0.48 \\
\hline AE48 & 25.8 & 0.52 \\
\hline AE52 & 23.8 & \\
\hline
\end{tabular}

Table 3 Compressive strengths for mixtures with varying cement contents at different ages $(w / c=0.48)$.

\begin{tabular}{|c|c|c|}
\hline \multirow[t]{2}{*}{ Label } & $\begin{array}{l}\text { Compressive } \\
\text { strength }\end{array}$ & $\begin{array}{l}\text { Age of } \\
\text { concrete }\end{array}$ \\
\hline & $\mathrm{MPa}$ & days \\
\hline L48 & 8.1 & 7 \\
\hline N48 & 15.5 & 7 \\
\hline R48 & 19.0 & 7 \\
\hline L48 & 10.3 & 14 \\
\hline N48 & 18.0 & 14 \\
\hline R48 & 21.5 & 14 \\
\hline L48 & 12.5 & 28 \\
\hline N48 & 20.5 & 28 \\
\hline R48 & 24.8 & 28 \\
\hline
\end{tabular}


transmission function in the frequency domain, reducing incoherent noise (Song et al., 2003). Figure 1 shows typical time domain response signals. The arrival of the direct Rayleigh surface wave coincides with the large first significant valley in the signal. Velocity measurements are dependant on the uncertainty of the measurement in the time signal. In this study, the surface wave time measurements vary by $\pm 0.05 \mu \mathrm{s}$ and UPV time measurements by $\pm 0.1 \mu \mathrm{s}$.

\section{Experimental results}

\subsection{Steel verification}

The experimental setup, shown in Fig. 2 with $50 \mathrm{~mm}$ spacing, was first applied to a homogeneous steel block in order to verify proper function of the acquisition and processing systems. The steel block was initially inspected with the use of high frequency normal and angle beam ultrasonic transducers; no flaws were detected. A transmission value of 0.71 is expected based only on beam spreading of the signal, given that no flaws were observed and that steel exhibits very low material signal loss. Surface wave velocity measurement was also carried out.

Figure 4 shows a typical transmission signal obtained from the steel block. In it, a flat constant response is observed throughout a wide range of frequencies. The transmission value coincides with the theoretical prediction of 0.71 . Several frequency ranges and spacings were tested giving similar results. Surface wave velocity was consistently measured to be $3050 \mathrm{~m} / \mathrm{s}$, which is slightly lower than the expected value of $3200 \mathrm{~m} / \mathrm{s}$ as reported by Bray and Stanley (1997).

\subsection{Concrete results}

Surface wave and UPV measurements were performed on each slab on the day that compressive strength was determined from the companion cylinders. For each slab, transmission data were obtained from five test locations. UPV and surface wave velocity data were also obtained at multiple locations across the slab's surface and averaged.

After the whole set of experiments was performed, combinations of raw and normalized data were used to investigate correlations with concrete's compressive strength. Linear, second order polynomials, exponential and logarithmic relations between strength and NDE parameters were considered. The quality of each correlation was determined by the square root of the average squared errors:

$$
\text { error }=\sqrt{\frac{\sum_{i=1}^{n}\left(f^{\prime} c_{i-\text { predicted }}-f^{\prime} c_{i-\text { measured }}\right)^{2}}{n}}
$$

where $n$ is the total number of strength data points, $f^{\prime} c_{i-}$ predicted is the predicted compressive strength for a given correlation at a particular value, and $f^{\prime} c_{i \text {-measured }}$ is the actual compressive strength obtained from companion cylinders.

Correlation between compressive strength and UPV, a common NDT approach, gave reasonably good results with a simple linear fit, as shown in Fig. 5. Average error for all specimens (Eqn. 4) was calculated to be 6.76 MPa. The data, however, show some spread and moreover the sensitivity of the approximation is only

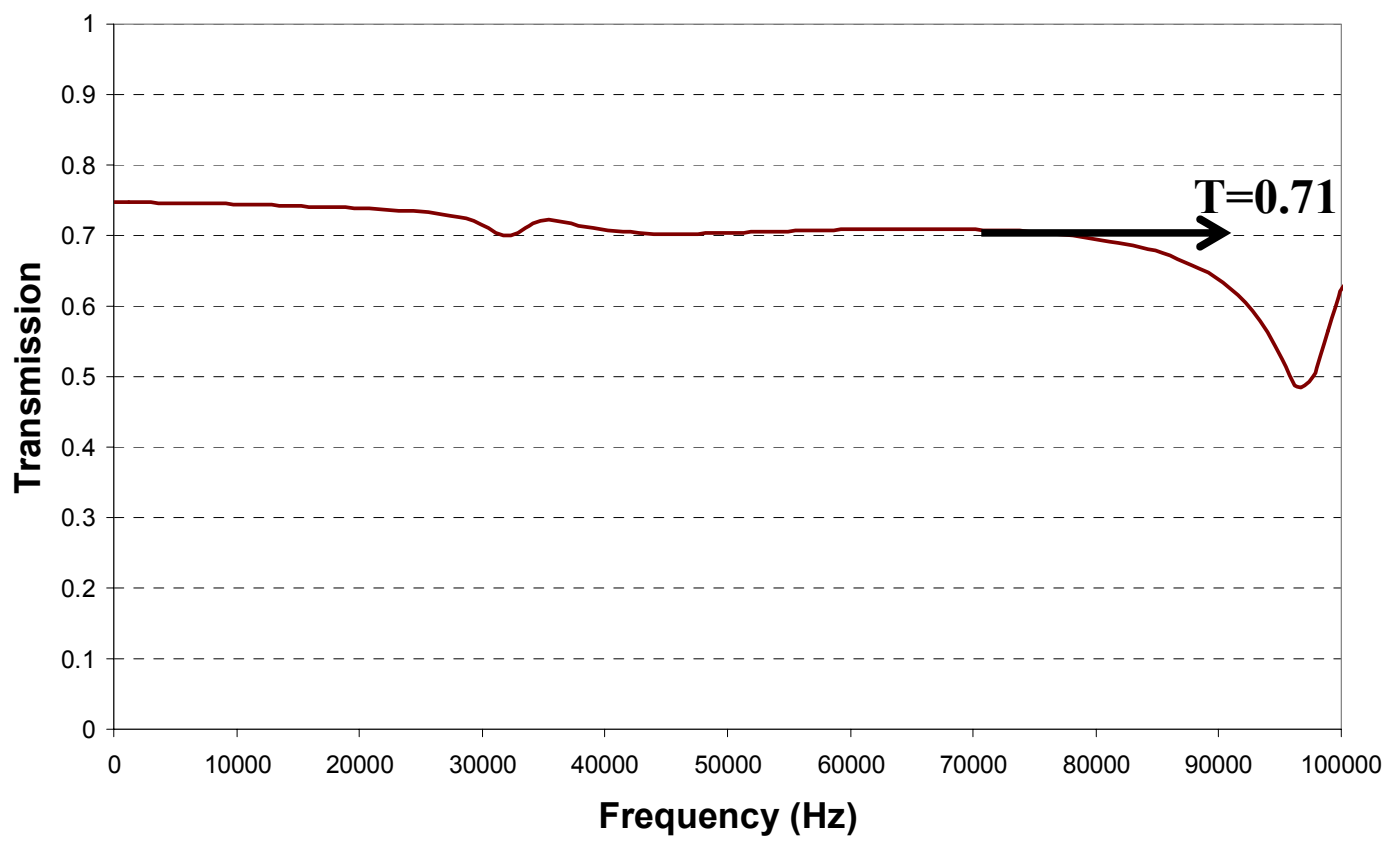

Fig. 4 Typical transmission function in the frequency domain for the steel block. Theoretical ideal value indicated with arrow. 
Table 4 Average squared compressive strength errors for different fits. Sensitivities have also been included.

\begin{tabular}{|c|c|c|c|c|c|}
\hline \multirow[b]{2}{*}{ NDE Parameter } & \multicolumn{4}{|c|}{ Error (MPa) } & Sensitivity \\
\hline & Linear & $\begin{array}{l}2^{\text {nd }} \text { order } \\
\text { Polynomial }\end{array}$ & Exponential & $\mathrm{ACI}$ & $(\%)$ \\
\hline Norm. Transmission & 10.4 & 9.9 & 10.8 & 10.7 & 37 \\
\hline Norm. $V_{R}$ & 5.9 & 4.3 & 5.3 & 5.3 & 13 \\
\hline Norm. UPV & 6.8 & 6.5 & 6.6 & 6.6 & 13 \\
\hline Norm. Transmission ${ }^{\wedge} 10$ & 10.7 & 10.5 & 10.9 & 10.7 & 99 \\
\hline Norm. $V_{R} \wedge 10$ & 5.0 & 4.6 & 4.7 & 5.3 & 75 \\
\hline Norm. UPV $\wedge 10$ & 6.5 & 6.5 & 6.6 & 6.6 & 76 \\
\hline (Norm. $T+$ Norm. $\left.V_{R}\right)$ & 9.2 & 8.9 & 9.7 & 9.6 & 21 \\
\hline$\left(\text { Norm. } T+\text { Norm. } V_{R}\right)^{\wedge} 10$ & 7.4 & 7.2 & 7.9 & 7.4 & 76 \\
\hline
\end{tabular}

$13 \%$. Sensitivity here is defined as the relative change in the selected parameter with respect to the change in the compressive strength. For the case in Fig. 5, it is the relative decrease in the maximum UPV value to the lowest. Higher values of sensitivity are desired because it enhances the differentiation between different concrete compressive strengths.

A similar approach is taken for surface wave velocity and transmission. Surface wave velocity had sensitivity close to that of UPV, although spread and average error were less: $5.92 \mathrm{MPa}$. Figure 6 shows compressive strength compared to surface wave velocity data; sensitivity is shown also to be $13 \%$. Transmission shows the largest sensitivity, but at the same time the largest error:10.4 MPa. Figure 7 shows that the sensitivity of transmission data is $36 \%$.

Alternative approaches to better predict the compres- sive strength of concrete were investigated. First, data were normalized to simplify data merging. The normalized data, those data raised to the tenth power, and combinations of transmission and surface wave velocity were considered. The aim was to reduce spread and increase sensitivity of the measurements. Table 4 shows the errors obtained with the different fits for each particular parameter. The column marked 'ACI' represents the approach described in ACI 228.1R-03 in which the natural logarithms of the cylinders compressive strengths are plotted against the logarithms of the inplace test results, and a linear relationship is then used to relate them and that also serves to calculate errors (ACI, 2003).

Table 4 shows that surface wave velocity measurements provide the best correlation to strength (least error). In fact surface wave velocity shows $13 \%$ less error

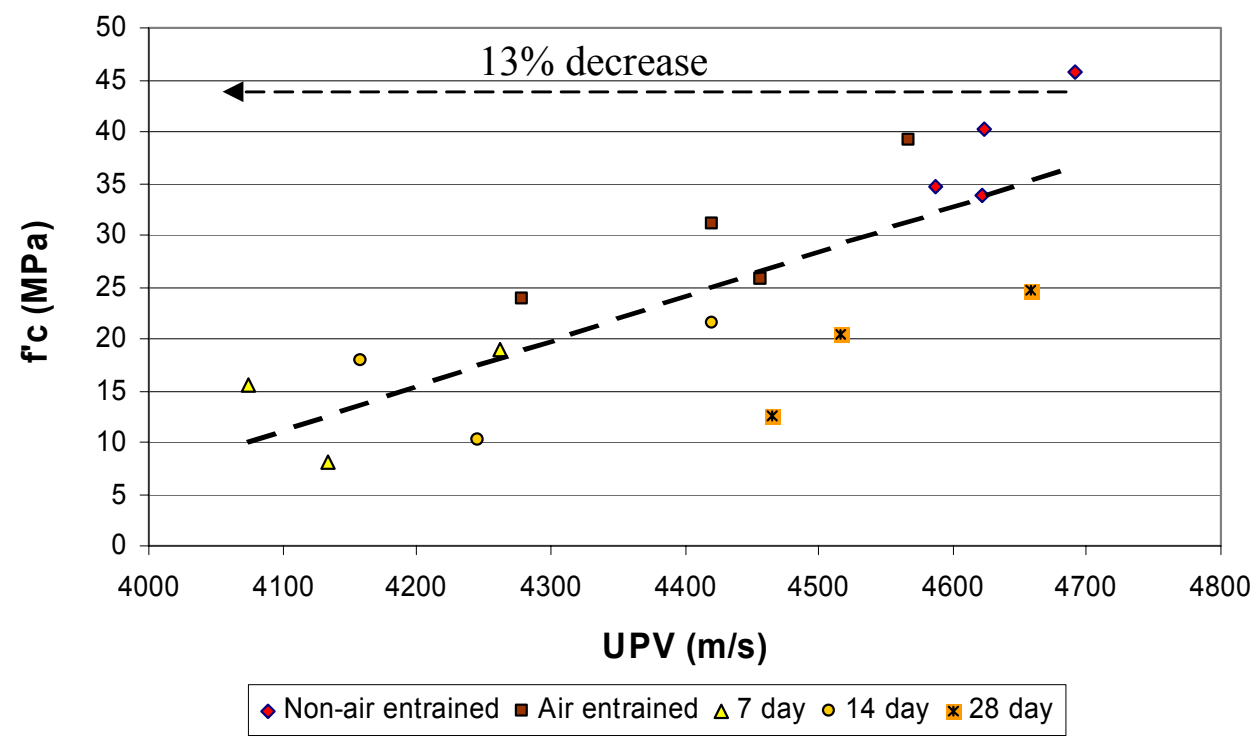

Fig. 5 Compressive strength $\left(f_{c}\right)$ vs. UPV data (points) with linear best fit line. 


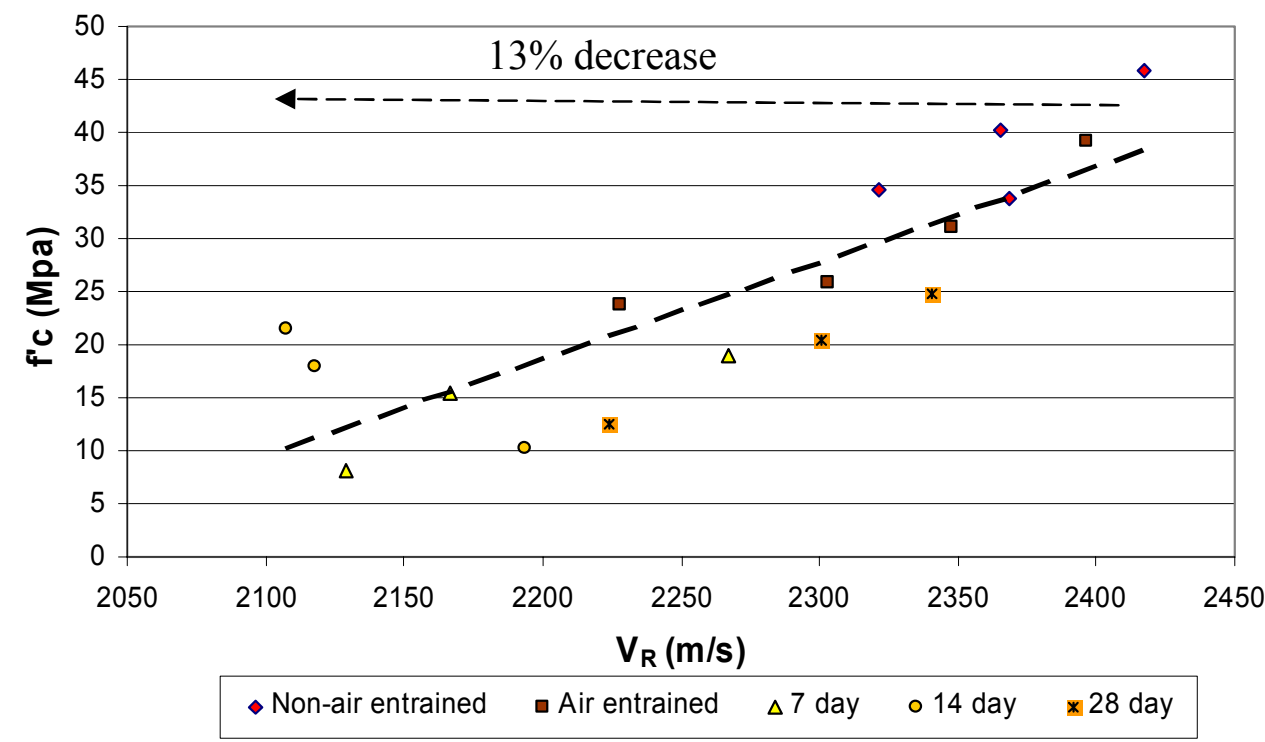

Fig. 6 Compressive strength $\left(f_{c}\right)$ vs. surface wave velocity data (points) with linear best fit line.

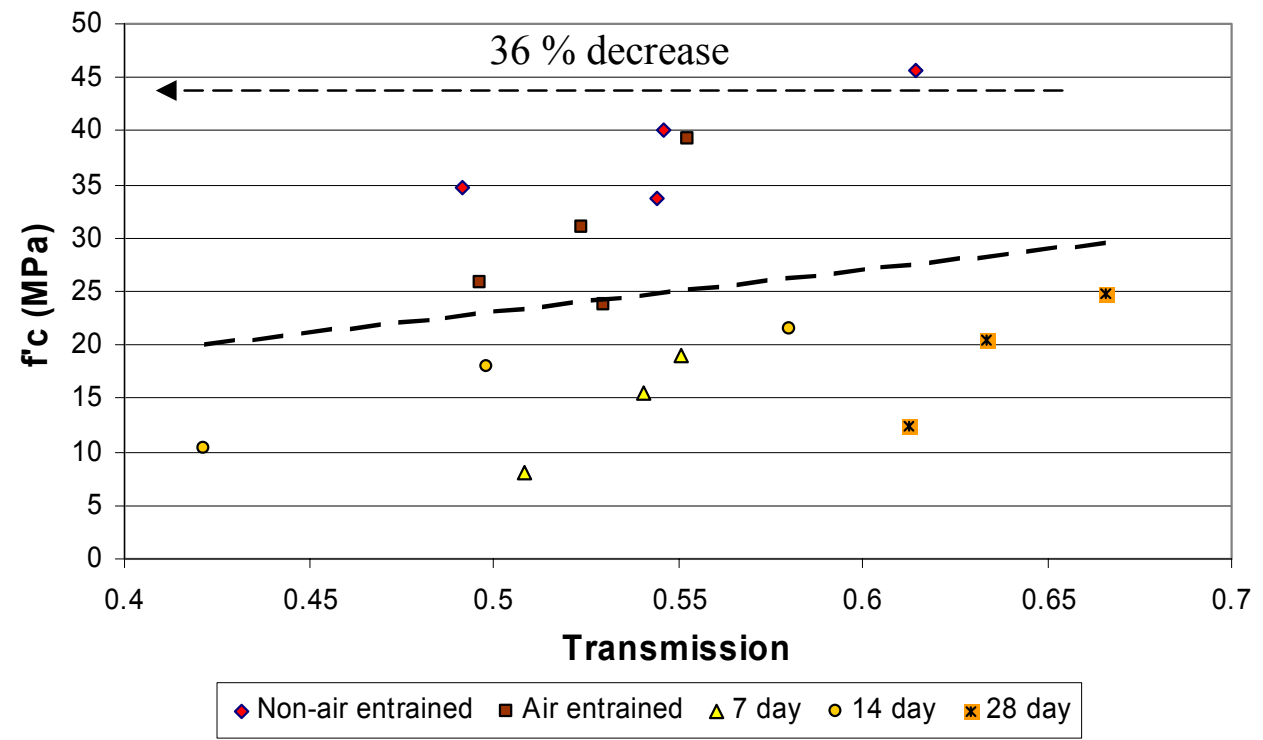

Fig. 7 Compressive strength $\left(f_{c}\right)$ vs. transmission data (points) with linear best fit line.

than UPV. When this data set is raised to the tenth power, error is further reduced in most cases. There are slight differences among fits; $2^{\text {nd }}$ order polynomial fit gives the best results overall. The ACI method gives errors consistent to those of the other fits. Combined data do not give improved results when compared to the small errors observed with $V_{R}$ alone. Sensitivity was found to be largest for transmission data.

\section{Conclusions}

The following conclusions are drawn from the work presented in this paper:

a. Usable surface wave data can be collected from concrete. The self-compensating scheme enables measurement of surface wave signal transmission.

b. Through thickness P-wave velocity measurements correlate fairly well to concrete compressive strength, although they are not suitable for pavement 
structures.

c. Surface wave velocity and transmission also correlate well to concrete strength and are suitable for pavement structures.

d. Normalized surface wave velocity raised to the tenth power provides the most accurate and sensitive estimates of in-place strength, showing $25 \%$ reduction in predicted strength error compared to UPV.

e. Transmission data were found to be the most sensitive to strength variations although the estimates of in-place strength were the less accurate because of data variability.

\section{Acknowledgements}

The work reported here was carried out under funding from the Virginia Transportation Research Council through project 68707 . The authors also gratefully acknowledge assistance from Salvador Villalobos and Gonzalo Cetrangolo with the laboratory work.

\section{References}

Achenbach, J. D. (1984). "Wave propagation in elastic solids." Amsterdam: Elsevier Science Publishers.

ACI Committee 228, (2003). "In-place methods to estimate concrete strength (ACI 228.1R-03)." Farmington Hills: American Concrete Institute.

Bray, D. and Stanley, S. (1997). "Nondestructive evaluation: A tool in design, manufacturing, and service." Boca Raton: CRC Press.

Cho, Y. (2003). "Non-destructive testing of high strength concrete using spectral analysis of surface waves." NDT\&E International, 36 (4), 229-235.

Popovics, J. S., Song, W. J., Ghandehari, M., Subramaninam, K., Achenbach, J. D. and Shah, S. P. (2000). "Application of surface wave transmission measurements for crack depth determination in concrete." ACI Materials Journal, 97 (2), 127-135.

Popovics, S., Rose, J. and Popovics, J. S. (1989). "The behavior of ultrasonic pulses in concrete." Cement and Concrete Research, 20 (2), 259-270.

Sellick, S. F., Landis, E. N., Peterson, M. L., Shah, S. P. and Achenbach, J. D. (1998). "Ultrasonic investigation of concrete with distributed damage." ACI Materials Journal, 95 (1), 27-36.

Song, W. J., Popovics, J. S., Aldrin, J. and Shah, S. (2003). "Measurement of surface wave transmission coefficient across surface-breaking cracks and notches in concrete." Journal of Acoustical Society of America, 113 (2), 717-725.

Warnemuende, K. and Wu, H. C. (2004). "Actively modulated acoustic nondestructive evaluation of concrete." Cement and Concrete Research, 34 (4), 563-570. 